\title{
PENGENALAN DIGITAL MARKETING DALAM UPAYA MENINGKATKAN PENGHASILAN IBU RUMAH TANGGA (IRT) MAJLIS TAKLIM AI AULADIYAH
}

\author{
Liana Dwi Septiningrum, Khotimatus Sadiyah, Julian Muhammad Hasan, \\ Dewi Rani Gustiasari, Ita Darsita \\ Universitas Pamulang \\ Email: dosen02046@unpam.ac.id
}

\begin{abstract}
Marketing is an important element of running a business. Many business people who take the time to think of what marketing methods are right so that the goods they sell sell in the market, because the success of the business depends on what methods / ways of marketing and how that is done by businesses, especially the UMKM. The main problem faced by housewives is the lack of knowledge in marketing both conventionally (offline) and online, especially e-commerce. The lack of knowledge of housewives about digital marketing has inspired the community service team to deliver socialization and provide training on the use of this information and communication technology. If housewives understand the importance of digital marketing for business opportunities, they are expected to be motivated to use digital marketing as a means of communication and business opportunities for their business, and can practice it directly by utilizing social media. Based on the main problems of partners, namely the lack of marketing management information, the solution offered to partners is to provide material related to digital marketing, offline marketing to increase revenue. The method used is lecture, question and answer, and simulation. The target to be achieved in community service activities is the implementation of the introduction of digital marketing in an effort to increase the income of housewives in order to become a prosperous family. The program's output targets are scientific articles published through the journal ISSN, and increased empowerment of housewives and the ability to take advantage of marketing opportunities through online and offline media.
\end{abstract}

Keywords: Introduction to Digital Marketing, Marketing, Increase Income of Housewives

\begin{abstract}
Abstrak
Pemasaran merupakan elemen penting menjalankan sebuah bisnis. Banyak pelaku bisnis yang meluangkan waktunya untuk memikirkan metode pemasaran apa yang tepat agar barang yang dijualnya laku di pasaran, karena sukses tidaknya bisnis bergantung pada metode/ cara pemasaran apa dan bagaimana yang dilakukan oleh pelaku usaha khususnya para pelaku UMKM. Masalah utama yang dihadapi IRT ialah kurangnya pengetahuan dalam memasarkan baik secara konvensional (offline) maupun secara
\end{abstract}


online, khususnya e-commerce. Minimnya pengetahuan IRT (Ibu Rumah Tangga) mengenai digital marketing menginspirasi tim pengabdian kepada masyarakat untuk menyampaikan sosialisasi dan memberikan pelatihan mengenai penggunaan teknologi informasi dan komunikasi ini. Jika pelaku ibu rumah tangga (IRT) paham akan pentingnya digital marketing bagi peluang bisnis usaha, diharapkan mereka akan termotivasi untuk menggunakan digital marketing sebagai sarana komunikasi dan peluang bisnis untuk usahanya, serta dapat mempraktikkannya secara langsung dengan memanfaatkan media sosial. Berdasarkan permasalahan utama mitra yaitu kurangnya informasi manajemen pemasaran maka solusi yang ditawarkan kepada mitra ialah dengan memberikan materi terkait dengan marketing digital, pemasaran offline untuk dapat meningkatkan penghasilan. Dengan metode yang digunakan adalah ceramah, tanya jawab, dan simulasi. Adapun target yang ingin dicapai dalam kegiatan pengabdian kepada masyarakat ini adalah pelaksanaan pengenalan digital marketing dalam upaya meningkatkan penghasilan ibu rumah tangga (IRT) agar menjadi keluarga sejahtera. Target luaran program ini adalah artikel ilmiah yang dipublikasikan melalui jurnal berISSN, dan peningkatan keberdayaan ibu rumah tangga (IRT) serta kemampuan dalam memanfaatkan peluang pemasaran melalui media online dan offline.

Kata Kunci: Pengenalan Digital Marketing, Pemasaran, Meningkatkan Penghasilan Ibu Rumah Tangga

\section{A. PENDAHULUAN}

Perkembangan tehnologi berkembang sangat pesat, sehingga mau tidak mau masyarakat harus mengikuti perkembangan tehnologi tersebut, bila tidak akan tertinggal. Penggunaan sosial media adalah alatpemasaran yang paling ampuh karena semua orang dari berbagai latar belakang yang berbeda, sangat aktif menggunakannya. Dengan sosial media pelaku usaha dapat menjalin interaksi secara luas dengan berbagai kalangan, dengan yang murah dan sesuai untuk memasarkan produkmereka, sehingga apa yang ditawarkan memiliki peluang besar untuk terjual.Salah satu Usaha atau bisnis lewat internet (dengan menggunakan elektronik) ini sering diseut dengan electronic commerce (E-Commerce) atau Electronic business (E-Business).

Pemasaran digital adalah suatu usaha untuk mempromosikan sebuah merek dengan menggunakan media digital yang dapat menjangkau konsumen secara tepatwaktu, pribadi, dan relevan. Tipe pemasaran digital mencakup banyak teknik dan praktik yang terkandung dalam kategori pemasaran internet. Dengan adanya ketergantungan pemasaran tanpa internet membuat bidang pemasaran digital menggabungkan elemen utama lainnya seperti ponsel, SMS (pesan teks dikirim melalui ponsel), menampilkan iklan spanduk, dan digital luar. Pemasaran digital turut menggabungkan faktor psikologis, humanis, antropologi, dan teknologi yang akanmenjadi media baru dengan kapasitas besar, interaktif, dan multimedia. Hasil dari era baru berupa interaksi antara produsen, perantara pasar, dan konsumen. Pemasaran melalui digital sedang diperluas untuk mendukung pelayanan perusahaan dan keterlibatan dari konsumen.

Di Indonesia, digital marketing sudah sangat berkembang mengingat pengguna internet di Indonesia yang semakin meningkat. Menurut survey yang dilakukan oleh Asosiasi Pengguna Jasa Internet Indonesia (APJII) menunjukkan bahwa penetrasi dan perilaku 
pengguna internet di Indonesia yang selalu meningkat 10\% tiap tahunnya. Di tahun 2017, tercatat sebanyak 143,25 juta penduduk telah menggunakan internet. Tidak heran apabila digital marketing dapat berkembang secara pesat dalam memasarkan produknya di Indonesia.

Berbicara tentang perkembangan digital marketing, khusus tahun depan sepertinya trend ini kian meningkat dan semua orang bahkan company besar pun perlu turun ke digital dan meluaskan pemasarannya tanpa menghilangkan teknik lama yang meskipun tidak begitu efektif, namun juga tetap bisa memberikan kontribusi pada income. Dengan beragam hadirnya platform digital yang semakin beragam, tahun 2019 dipastikan trend pemasaran digital semakin naik dan banyak user yang akan mengoptimalkan pernggunaan digital platform ini untuk berbisnis.

Tujuan utama digital marketing adalah sebagai pemasaran penjualan produk dan jasa, salah satunya yaitu sebagai berikut:

1.Target Pemasaran Yang Tepat

Tujuan utama dari "Digital Marketing" adalah pemasaran yang memanfaatkan alat atau media digital untuk menjangkau target konsumen secara cepat, tepat dan luas. Selain itu juga bisa lebih efektif dan efisien dalam penggunaan dana iklan untuk kepentingan usaha atau bisnis.

\section{Analysis Digital}

Setelah menentukan target, yaitu menganalisa untuk menerapkan sistem digital marketing yang paling efektif dan efisien. Ada beberapa macam alat sebagai halaman analisa untuk mengukur sebuah iklan, prilaku user, dan termasuk penggunaan anggaran iklan, sehingga benar-benar sesuai target pemasaran.

Salah satu media komunikasi yang dapat digunakan pelaku usaha untuk mempromosikan usahanya adalah komunikasi media maya atau media internet. Para Ibu Rumah Tangga (IRT) Majlis Taklim Al-Auladiyah dapat memanfaatkan e-commerce dan marketplace yang memberikan peluang yang besar untuk bisa mengekspansi penjualan produk mereka melalui media digital serta penambahan pendapatan keluarga. Para IRT perlu memanfaatkan bermacam cara untuk melakukan promosi dan meningkatkan penjualan produk mereka, salah satunya dengan memanfaatkan peluang yang ada agar dapat tercipta UMKM di daerah tersebut. Media sosial berpotensi untuk membantu pelaku UMKM dalam memasarkan produknya (Stelzner, 2012). Aplikasi media sosial tersedia mulai dari pesan instan hingga situs jejaring sosial yang menawarkan pengguna untuk berinteraksi, berhubungan, dan berkomunikasi satu sama lain. Aplikasi-aplikasi ini bermaksud untuk menginisiasi dan mengedarkan informasi online tentang pengalaman pengguna dalam mengonsumsi produk atau merek, dengan tujuan utama meraih (engage) masyarakat. Dalam konteks bisnis, people engagement dapat mengarah kepada penciptaan profit.

Berdasarkan uraian masalah tersebut, maka disepakati bahwa terdapat masalah utama, yaitu Minimnya pengetahuan IRT (Ibu Rumah Tangga) mengenai digital marketing menginspirasi tim Pengabdian kepada Masyarakat (PKM) yang dilakukan oleh beberapa dosen dari fakultas ekonomi Prodi Akuntansi, Universitas Pamulang. Kegiatan ini merupakan bentuk keterlibatan perguruan tinggi dalam melaksanakan Tridharma perguruan tinggi dan memberikan pemahaman dan sosialisasi kepada pelaku UMKM mengenai strategi-strategi pemasaran yang tepat agar dapat mengoptimalkan profit yang diinginkan, sehingga terbentuklah kegiatan pengabdian kepada masyarakat dengan judul "Pengenalan Digital Marketing Dalam Upaya Meningkatkan Penghasilan Ibu Rumah Tangga (IRT) Majlis Taklim Al-Auladiyah". 


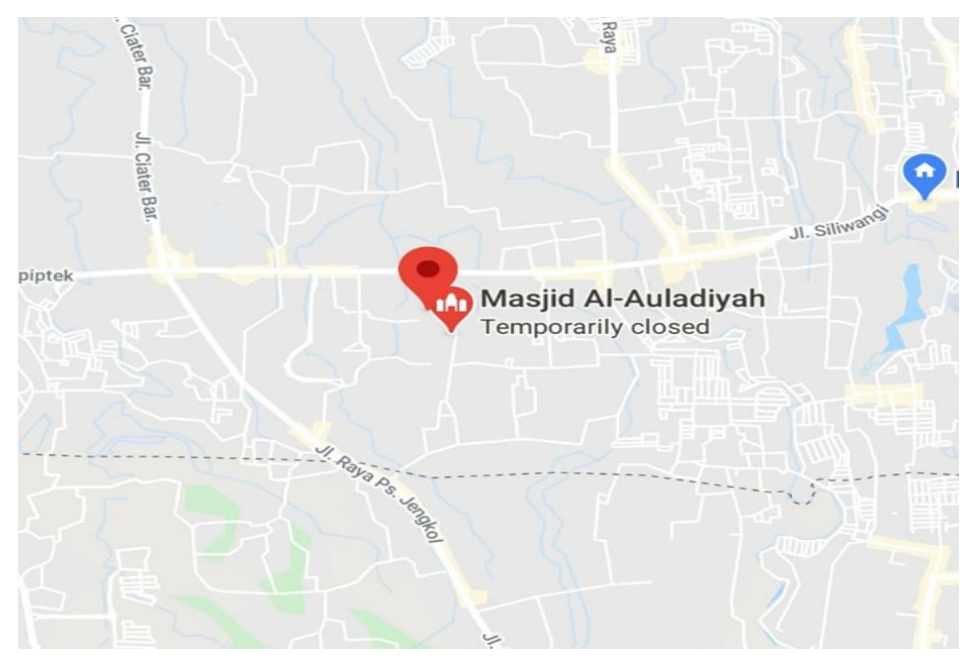

Gambar 1. Lokasi Tempat Pelaksanaan PKM

Adapun sasaran pengabdian yang kami tuju yaitu Ibu Rumah Tangga Majlis Taklim AlAuladiyah di Tangerang Selatan. Adapun target luaran program ini adalah artikel ilmiah yang dipublikasikan melalui jurnal berISSN, dandiharapkan mereka akan termotivasi untuk menggunakan digital marketing sebagai sarana komunikasi dan peluang bisnis untuk usahanya, serta dapat mempraktikkannya secara langsung dengan memanfaatkan media sosial.

\section{B. METODE PELAKSANAAN KEGIATAN}

Pelaksanaan program kegiatan Pengabdian Kepada Masyarakat (PKM) ini melalui beberapa tahapan yang telah dilaksanakan, antara lain dapat digambarkan dalam alur berikut: 1. Tahap Persiapan

a. Kegiatan Observasi dan Perizinan

Observasi dilakukan dengan melakukan survey pada lokasi yang akan dijadikan kegiatan Pengabdian Kepada Masyarakat (PKM) yakni Majlis Taklim Al-Auladiyah Jalan AMD. Babakan Pocis, Bankti Jaya Setu-Tangerang Selatan. Survey dilakukan 3 kali untuk menentukan titik yang tepat yang akan dijadikan sebagai point kegiatan. Peserta yang hadir sebanyak 30 orang terdiri dari Perempuan (Ibu Rumah Tangga). Dalam tahapan perizinan para dosen berkordinasi dengan pihak terkait, yaitu Ketua DKM Majlis Taklim Al-Auladiyah Bpk H. Basuki Boan dimana kegiatan PKM akan dilaksanakan.

b. Penyusunan RAB

Rencana Anggaran dan Belanja dipersiapkan dalam hal pembelian belanja bahan seperti: Honor narasumber, cinderamata/plakat, konsumsi, sertifikat, materi, pembuatan jurnal dan door prize serta beberapa peralatan lainya yaitu: tempat pelatihan, sound sistem, laptop dan LCD proyektor.

c. Pengajuan Proposal

Proposal kegiatan PKM diajukan pada tanggal 27 Maret 2020 dan setelah melalui proses review, disetujui oleh Ketua LPPM Bapak Ali Madinsyah pada tanggal 18 April 2020. 


\section{Tahap Implementasi/ pelaksanaan kegiatan}

Pada sesi ceramah yang disampaikan oleh Julian Muhammad Hasan, Sos., M.A, selaku narasumber membahas mengenai Marketing Digital dan manfaat dari penggunaan media online di era digital saat ini.

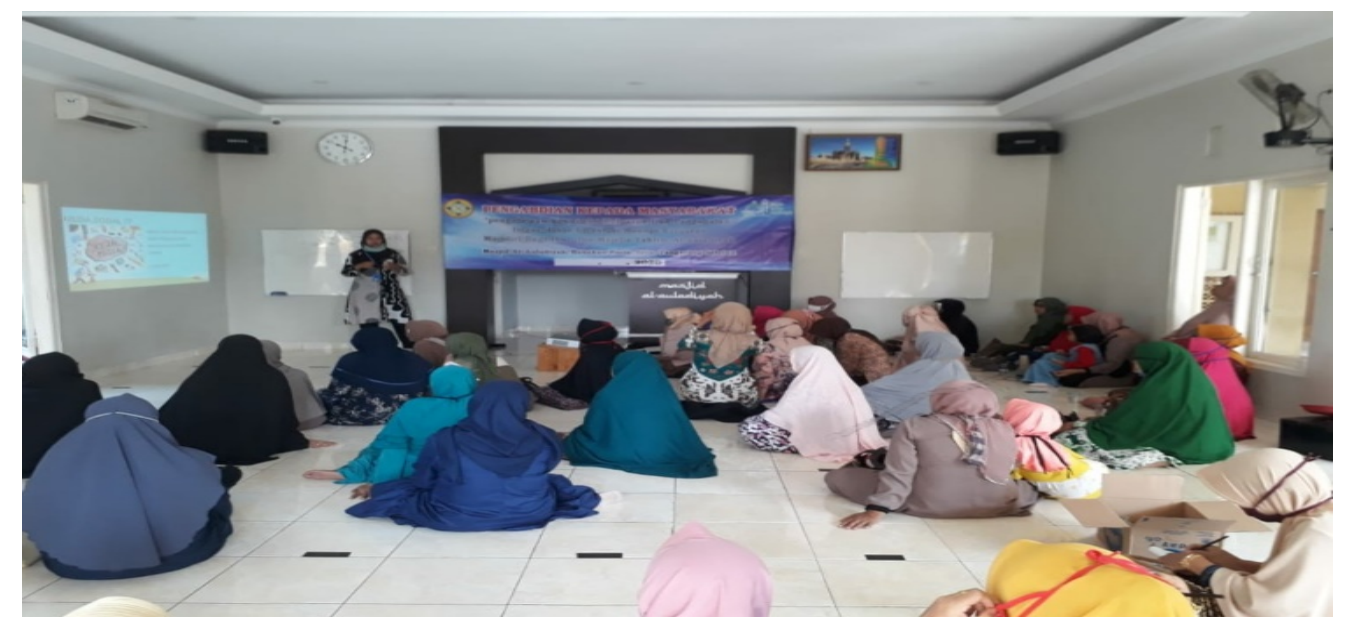

\section{Gambar 2. Pemaparan Materi Digital Marketing oleh salah satu Narasumber}

Pada sesi tanya jawab, membahas permasalahan minimnya pengetahuan tentang aplikasi layanan online digital.

Pada sesi diskusi, para ibu rumah tangga diberikan pemahaman tentang aplikasi yang dibutuhkan dalam pemasaran produk secara digital dan pelatihan dalam menggunakan perangkat maupun aplikasi sosial media, sehingga dari aplikasi digital pelaku usaha dapat membuat atau menggunakan salah satu atau beberapa situs penjualan online secara minim biaya.

Dilanjutkan dengan program pelatihan pemasaran online pada pelaku usaha seperti pada Whatsapp, Facebook, Instagram, serta situs penjualam online lainnya. Salah satu simulasi marketplace simulasi pemasaran online yaitu pada marketplace tokopedia yang di bantu oleh ibu Liana Dwi Septiningrum, S.E, M.M, Ibu KhotimatusSadiyah, S.Si, M.M, Ibu Dewi Rani dan Bapak Ita Darsita, S.E., M.M.

\section{HASIL DAN PEMBAHASAN}

\section{Tahap Persiapan}

Kegiatan Pengabdian Masyarakat ini dilakukan di Masjid Al-Auladiyah Jalan AMD. Babakan Pocis, Bankti Jaya Setu-Tangerang Selatan. Kegiatan pengabdian ini dihadiri oleh anggota Majlis Taklim Al-Auladiyah yang anggotanya terdiri dari ibu-ibu rumah tangga yang selain berprofesi sebagai ibu rumah tangga juga bekerja sebagai penghasil produk makanan. Kegiatan ini disambut positif oleh ibu-ibu anggota Majlis Taklim Al-Auladiyah. Pada hasil pengamatan yang dilakukan oleh para dosen Universitas pamulang, ditemukan permasalahan kurangnya pengetahuan dalam memasarkan baik secara konvensional (offline) maupun secara online. Berdasarkan permasalahan yang dihadapi oleh para ibu rumah tangga tersebut maka kami memberikan solusi kepada mitra ialah dengan memberikan materi terkait dengan marketing digital, pemasaran offline untuk dapat meningkatkan penghasilan para ibu rumah tangga (IRT). Adapun Materi-materi yang diberikan adalah sebagai berikut: 
a. Materi tentang Manajemen Pemasaran

Perkembangan Usaha Kecil dan Menengah di Indonesia terus berkembang dikarenakan pertumbuhan ekonomi yang terus meningkat. Perkembangan ini tentunya menuntut pelaku usaha untuk lebih kreatif dan inovatif dalam menyusun strategi pemasaran yang efektif. Sebuah usaha akan sulit untuk berkembang jika pelaku usahanya tidak mengetahui bagaimana cara memasarkan suatu produk dengan efektif. Berikut adalah beberapa strategi yang dapat Anda gunakan untuk memasarkan bisnis.

1) Membuat Produk yang Unik

Buatlah produk yang unik dan memiliki kelebihan dibandingkan produk lain yang sejenis. Pesaing tentu ada di mana-mana, jika produk atau jasa yang ditawarkan tidak memiliki kelebihan, maka akan sulit untuk bersaing. Selain unik dan berkualitas, produk yang ingin Anda jual juga harus bisa memenuhi kebutuhan konsumen. Seiring dengan perkembangan zaman dan teknologi, kebutuhan konsumen pun ikut berubah, sehingga, inovasi harus selalu dilakukan secara berkala. Hal ini untuk membantu dalam persaingan pasar dan membuat pelanggan loyal terhadap produk yang dijual.

2) Menjadi Networker

Networker adalah seseorang yang memiliki jaringan yang sangat luas dan memiliki sifat optimis dalam menjalankan bisnis. Jika Anda bukanlah seorang networker yang kompeten, Anda bisa mempekerjakan seorang tenaga pemasaran yang bisa diandalkan sebagai ujung tombak untuk perluasan jaringan.

3) Menentukan STP

STP adalah singkatan dari segmenting, targeting, dan positioning. Di mana tiga hal tersebut saling berhubungan satu sama lainnya. Untuk memasarkan produknya, harus menentukan segmentasi pasar (segmenting) yaitu dengan menempatkan konsumen dalam sub-kelompok di pasar produk, sehingga para pembeli memiliki tanggapan yang hampir sama dengan strategi pemasaran dalam penentuan posisi perusahaan. Jika telah menentukan segmentasinya, selanjutnya menentukan pasar (targeting), di mana harus mengevaluasi berbagai segmen tersebut untuk memutuskan siapa yang menjadi target market.Setelah menentukan segmenting dan targeting, selanjutnya menentukan posisi (positioning) produk yang merupakan kombinasi kegiatan pemasaran yang dilakukan manajemen untuk memenuhi kebutuhan dan keinginan setiap pasar sasaran. Ketiga strategi tersebut harus dilakukan dengan baik untuk mencapai pemasaran yang sukses.

4) Memanfaatkan E-commerce

Dengan memanfaatkan e-commerce, bisnis memiliki peluang untuk menjangkau pasar yang luas bahkan global. E-commerce dalam dunia bisnis dapat mendukung pemotongan rantai distribusi, sehingga konsumen dapat memperoleh suatu produk dengan harga murah.

5) Konsisten

Konsistensi dalam menjalankan strategi pemasaran merupakan hal penting. Selain kreatif, pelaku usahajuga dituntut untuk bisa terus konsisten dalam menjalankan strategi pemasaran yang dipilih. Hal ini penting karena kepercayaan konsumen akan terbangun apabila pelaku usaha konsisten dibidang usaha yang digeluti dan menjadi ahli didalamnya. 


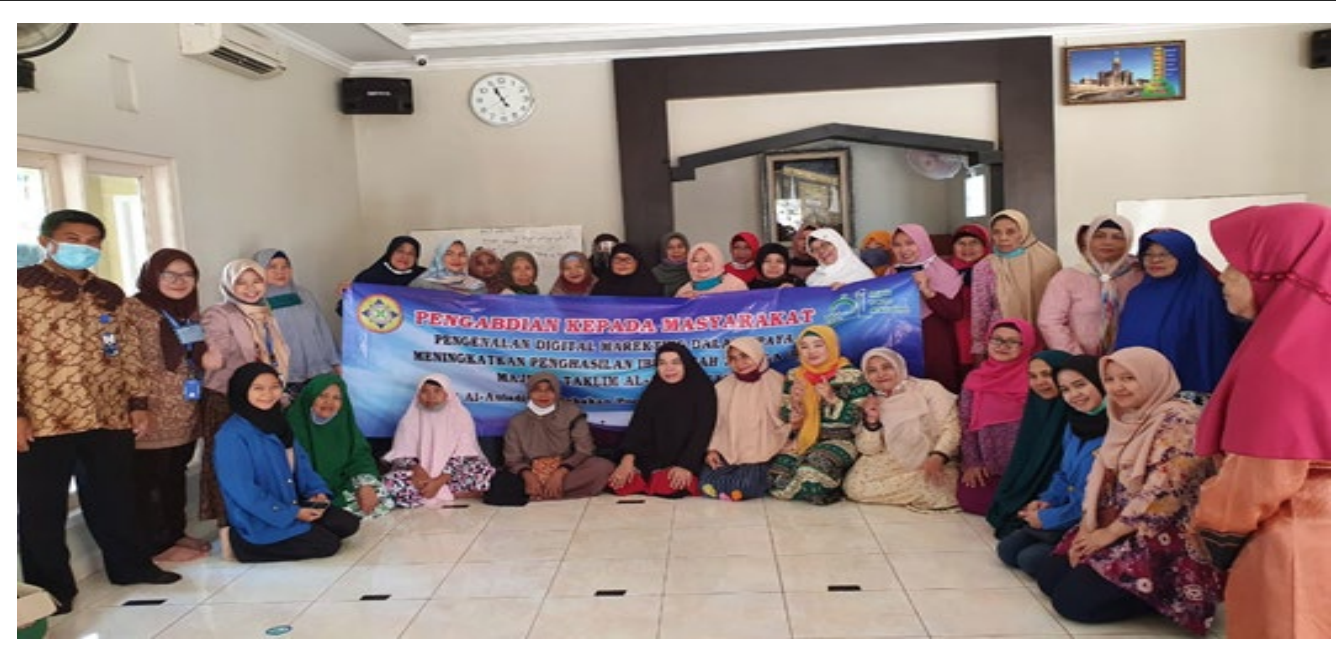

Gambar 3. Foto Bersama Para Peserta PKM dan Mahasiswa UNPAM

\section{KESIMPULAN DAN SARAN}

\section{Simpulan}

Kegiatan pelaksanaan Pengabdian Kepada Masyarakat (PKM) yang dilaksankan di Masjid Al-Auladiyah Jalan AMD. Babakan Pocis, Bankti Jaya Setu-Tangerang Selatan sudah dilalui, berbagai hal menarik diperoleh dari pelaksanaan kegiatan tersebut. Metode/ cara implementasi pemasaran menggunakan sosial media terbukti dapat meningkatkan pengembangan produk mitra bisnis baik darisisi pendapatan/omset maupun dari sisi biaya.

Kegiatan PKM ini telah memberikan kontribusi kepada pelaku bisnis/ mitra bisnis dengan memberikan solusi berupa pelatihan guna meningkatkan pengetahuan dalam penggunaan sosial media sebagai infrastruktur pemasaran produknya. Adapun kesimpulan dari kegiatan pengabdian masyarakat yang telah di lakukan adalah:

1. Anggota Majlis Taklim Al-Auladiyah melakukan pemasaran menggunakan aplikasi penjualan online pada Smartphone yang dimilikinya, yaitu dengan pembuatan akun tokopedia guna memasarkan produknya.

2. Anggota Majlis Taklim Al-Auladiyah melakukan inovasi pada kemasan produknya dengan menambahkan keterangan bahan baku dan tanggal kadar luarsa produk pada kemasan produknya.

3. Dengan menggunakan aplikasi penjualan online yang ada di situs penjualan dan sosial media, terbukti mengurangi biaya tenaga pemasaran, memperluas pasar sasaran dan jaringan pasar.

4. Disamping itu pula dari aplikasi penjualan online/ E-commerce mitra bisnis dapat melihat di kolom komentar pelanggan mitra bisnis, sehingga hal-hal yang baik tentang produk dari mitra bisnis dapat dipertahankan/ mungkin ditingkatkan sedangkan hal-hal yang kurang disukai oleh pelanggan segera dapat dicarikan perbaikannya

\section{Saran}

Pengabdian masyarakat diharapkan dapat dilakukan kembali di Masjid Al-Auladiyah Jalan AMD. Babakan Pocis, Bakti Jaya Setu-Tangerang Selatan karena masih banyak anggota Majlis Taklim Al-Auladiyah yang belum hadir secara penuh dikarenakan Pandemi Covid-19. 
Ucapan Terima Kasih

Penulis mengucapkan terima kasih yang tak terhingga kepada ketua Yayasan Sasmita Jaya, LPPM Universitas Pamulang, dan Pihak pengurus majlis taklim Al Auladiyah Pocis, Bakti Jaya Setu-Tangerang Selatan yang telah banyak memberikan dukungan dalam kegiatan PKM ini.

\section{DAFTAR PUSTAKA}

Aditya Wardhana. (2015). Analisis Faktor-Faktor Pembentuk Service Recovery Pada Top Brand Perusahaan Penyedia Jasa Rental Mobil Di Indonesia Berdasarkan Persepsi Pelanggan Korporasi. ISSN 2089-3590. EISSN 2303-2472.

Ali, Hasan. (2013). Marketing dan Kasus-Kasus Pilihan. Yogyakarta. CAPS (Center ForAcademicPublishing Service).

Kotler, Philip dan Armstrong, Gray. (2014). Prinsip-prinsip Manajemen. Edisi 14. Jilid 1. Jakarta, Erlangga.

Mullins, John W dan Walker Jr, Orville C. (2013). Marketing Management: A Strategic Decision-Making Approach, 8th Edition, McGraw-Hill International Edition.

Solihin, D. (2020), Pengaruh Kepercayaan Pelanggan dan Promosi Terhadap Keputusan Pembelian Konsumen Pada Online Shop Mikaylaku Dengan Minat Beli Sebagai Variabel Intervening. JURNAL MANDIRI: Ilmu Pengetahuan, Seni, dan Teknologi, Vol. 4, No. 1.

Solihin, D. (2020), Faktor-Faktor yang Mempengaruhi Kinerja Pemasaran Pada PT. Prima Ufuk Semesta Studi Pada Outlet Rekanan PT. Prima Ufuk Semesta di Wilayah JABODETABEK, Jurnal Semarak, Vol. 3 No.1.

Solihin, D., \& Wibawanto, E. (2020), Pengaruh Kualitas Pelayanan, Harga, Dan Promosi Terhadap Keputusan Pelanggan Dalam Memilih Klub Basket Satria Indonesia Tangerang Selatan, Jurnal Pemasaran Kompetitif, Vol. 3, No. 3.

Stelzner, MA (2012). Social Media Marketing Industry Report. How Marketers Are Using Social Media to Grow Their Business.

Tim LPPM Pamulang. (2016). Buku Panduan Penelitian dan Pengabdian Kepada Masyarakat. Universitas Pamulang. Tangerang Selatan

Tjiptono, Fandy. (2008). Strategi Pemasaran, Edisi Ketiga. Andi, Yogyakarta

https://www.dewaweb.com/blog/tren-digital-marketing/

https://www.dhadigital.com/apa-itu-digital-marketing/ 